This shows how necessary it is that the above method should be followed in detail to obtain correct results.

5. The writer uses for these determinations an especially constructed burette of 5 mils' capacity; the graduated part of the burette is about 230 millimeters in length so that a reading of 0.02 mils can be made with accuracy. The burette delivers 5 drops to the $0.1 \mathrm{mil}$. This type of burette is strongly recommended and it may be constructed from a graduated pipette. It is filled from the bottom by applying suction to a rubber tube attached to the top.

6. One must not confuse an acidity degree as determined by this method with the Soxhlet-Henkel degree, referred to principally in German literature. This German degree is two and a half times as great. Quite often dairymen determine milk acidity as lactic acid-ten mils milk titrated with ${ }_{10}^{N} \mathrm{NaOH}$ and the result multiplied by 0.9 . As the acidity of fresh milk is not due to lactic acid, but principally to acid phosphates, this degree is confusing and should be discontinued.

Columbus, Ohro,

363 KING Ave.,

JUNE 6, 1919.

\title{
BIBLIOGRAPHY.
}

I. Van Slyke, L. L., Proc. A. O. A. C., I893, I17; Hopkins, C. G., and Powers, W. A., Proc. A. O. A. C., $1895, \mathrm{1} 25$.

2. Cameron and Hurst, J. Am. Chem. Soc., 1904, 26, 905; Cameron and Bell, U. S. Dept. Agr., Bureat Soils, Bull. 4r, I907.

3. Van Slyke and Bosworth, Bull. 37, N. Y. Expt. Sta., Geneva, 1914.

4. Bosworth, A. W., J. Biol. Chem., 1915, 20-707.

5. Clark, W. M., J. Med. Research, 1915, 31-431.

6. Davidsohn, H., 2 Kinderheilk, 9, I I-8.

\section{A COMPARISON OF METHODS FOR THE DETERMINATION OF ETHYL,} ALCOHOL IN FERMENTED LIQUORS.*

\section{BY CHARLES H. ROGERS.}

Four methods have been recommended for the determination of the percentage of ethyl alcohol by weight and by volume in fermented liquors.

Metrod I. By Evaporation.-Determine the specific gravity of the sample at $\frac{15.6^{\circ}}{15.6^{\circ}} \mathrm{C}$. Carefully pour 50 or, preferably, roo mils of the sample to be examined into a porcelain evaporating dish and evaporate to about one-fourth of the original bulk. Make up to the original volume with distilled water and determine the specific gravity at $\frac{15 \cdot 6^{\circ}}{15.6^{\circ}} \mathrm{C}$. of this second or de-alcoholized portion. Add the figure $I$ to the original specific gravity, and from this subtract the second specific gravity. The difference will be the specific gravity corresponding to the alcohol in the sample. The percentage is found by consulting the specific gravity and percentage alcohol table in the Pharmacopoeia.

* Read before Northwestern Branch A. Ph. A. and Scientific Section Minnesota Pharmaceutical Association. 
MeTHod 2. By Distillation.-Determine the specific gravity of the sample at $\frac{15.6^{\circ}}{15.6^{\circ}} \mathrm{C}$. Into a distilling flask of 200 to 400 mils, capacity introduce a convenient quantity of the liquor, the quantity used depending on the nature of the sample. Dilute the liquid with distilled water and distil about $95 \mathrm{mils}$ into a standard roo mil volumetric flask. Make up to volume with distilled water at $15.6^{\circ} \mathrm{C}$. Take the specific gravity and by means of the alcohol tables interpolate for the percentage of alcohol by volume and the percentage by weight in the distillate. Multiply the percentage by volume in the distillate by the volume of distillate divided by the volume of original liquid used, this giving the percentage by volume in the original. If percentage of alcohol by weight in the original is desired, multiply the percentage by weight in the distillate by the weight of the distillate divided by the weight of the original sample taken. It is sometimes necessary to subject the original sample to special treatment before a distillation can be run, viz.: where essential oils, iodine, volatile acids, etc., are present.

METHOD 3. By Refractometer-Determine the specific gravity of the sample at $\frac{20^{\circ}}{4} \mathrm{C}$. and proceed as in Method 2. Make up to volume at $20^{\circ} \mathrm{C}$. Read the scale divisions on the instrument and, using the table which accompanies the instrument, convert them into percentage of alcohol by weight. The percentage by weight in the distillate may then be calculated to percentage by weight and volume in the original. This instrument is capable of great accuracy. It is, on the other hand, more limited in its range, giving indices of refraction between I.32 and 1.36 only. The principle on which the immersion refractometer is based is the same as in the Abbe refractometer and depends upon the observation of the border line of total reflection.

MeTHoD 4. By Vaporimeter (Geissler).-This particular instrument is suitable for determining the percentage of alcohol in comparatively low concentrations. The vaporimeter readings depend upon the varying vapor pressures of mixtures of alcohol and water at $100^{\circ}$. Correction tables for various boiling points of water, at different atmospheric pressures, accompany the instrument. The readings are taken directly from the accompanying Tralle and Richter scales, the former giving percentage by volume, the latter by weight.

TABLE I.

\begin{tabular}{|c|c|c|c|c|c|c|c|c|}
\hline \multirow{5}{*}{ “A” } & \multicolumn{2}{|c|}{ Evaporation. } & \multicolumn{2}{|c|}{ Distillation. } & \multicolumn{2}{|c|}{ Refractometer. } & \multicolumn{2}{|c|}{$\begin{array}{l}\text { As read from } \\
\text { Vaporimeter. }\end{array}$} \\
\hline & Wt. & Vol. & Wt. & Vol. & Wt. & Vol. & wt & Vol. \\
\hline & & & I. 65 & 2.120 & I. 832 & 2.34 & I. 90 & $2.33^{6}-\mathrm{c}$ \\
\hline & & & 2.10 & $2.69 \mathrm{I}$ & 2.100 & 2.69 & 2.00 & $2.476-c$ \\
\hline & & & I. 923 & $2.46 \mathrm{I}$ & I. $96 \mathrm{I}$ & $2.5 \mathrm{I}$ & 1. 96 & $2.412-5$ \\
\hline & & & I. 945 & $2.44 \mathrm{I}$ & I. 918 & 2.455 & & $2.40 \mathrm{I}-\mathrm{s}$ \\
\hline Aver. & & & 1.904 & 2.428 & I .952 & 2.499 & I . 95 & 2.406 \\
\hline "B" & & & 2.782 & 3.486 & 2.795 & 3.571 & 2.97 & 3.71 \\
\hline & & & 2.699 & 3.449 & 2.815 & 3.595 & 2.73 & 3.40 \\
\hline Aver. & & & 2.713 & 3.467 & 2.80 & $3 \cdot 583$ & 2.85 & $3 \cdot 55$ \\
\hline "C C" & & & 2.330 & 2.922 & 2.360 & 3.010 & 2.40 & 2.973 \\
\hline & & & 2.404 & 2.890 & $2.43 \mathrm{I}$ & 3.048 & $2 \cdot 35$ & 2.917 \\
\hline Aver. & & & 2.367 & 2.906 & 2.396 & 3.029 & 2.37 & 2.945 \\
\hline
\end{tabular}


The aforementioned four methods of procedure were applied to the examination of eight fermented liquors for the purpose of determining their relative accuracy as well as their limits of precision in the estimation of alcohol in fermented liquors. In Table $I$ is given the results of the analyses of the three beers, A, B and $C$. It will be noted that Method I (evaporation) cannot be used in the case of beers which do not run over 4 percent of alcohol by volume. It was found that after evaporating the original liquor and then making up to the original volume with distilled water, the resulting solution gave a specific gravity greater than one. It is quite apparent, therefore, that this process cannot be used with success with fermented liquors and preparations containing appreciable quantities of extractives and in which the alcohol does not exceed 5 percent.

TABLE, II.

\begin{tabular}{|c|c|c|c|c|c|c|c|c|}
\hline & Evap & ation. & Distil & tion. & Refrac & ometer. & $\begin{array}{l}\text { As rea } \\
\text { Vapor }\end{array}$ & $\begin{array}{l}\text { from } \\
\text { eter. }\end{array}$ \\
\hline & Wt. & Vol. & Wt. & Vol. & Wt. & Vol. & Wt. & vol. \\
\hline Sherry "A" & I8.250 & $22.38 \mathrm{I}$ & I 5.630 & 19.54 & I 5.730 & $19.6 \mathrm{ro}$ & 15.45 & 18.97 \\
\hline & $\mathrm{I} 8.22 \mathrm{I}$ & $22 \cdot 346$ & 15.370 & 19.24 & 15.530 & 19.440 & I 5.75 & I9. 35 \\
\hline & & & & & & & 15.50 & 19.02 \\
\hline & & & & & & & 16.10 & 19.80 \\
\hline & & & & & & & 16.20 & 19.91 \\
\hline & & & & & & & $\mathrm{I} 6.2 \mathrm{I}$ & 19.95 \\
\hline Aver. & 18.235 & $22 \cdot 364$ & 15.500 & 19.39 & 15.63 & 19.525 & I 5.87 & I9.50 \\
\hline Sherry " $\mathrm{B}$ " & I 8.130 & 22.237 & I $6.82 \mathrm{I}$ & 20.813 & I 7.18 & 21.096 & 18.60 & 22.85 \\
\hline & 18. I 38 & 22.246 & 17,180 & 21.096 & 17.609 & $2 \mathrm{I} .6 \mathrm{II}$ & I 8.55 & 22.90 \\
\hline & & & 17.029 & 20.834 & 17.962 & 22.030 & & 22.76 \\
\hline & & & & & 17.702 & 21.703 & & \\
\hline Aver. & 18.134 & $22.24 \mathrm{I}$ & 17.010 & 20.914 & 17.613 & 21.610 & I 8.575 & 22.84 \\
\hline Port & 14.815 & I 8.245 & 14.397 & 18.540 & I $4 \cdot 388$ & I 8.530 & $18.7^{\circ}$ & 22.90 \\
\hline & I 4.853 & $\mathrm{I} 8.29 \mathrm{I}$ & 14.453 & I 8.618 & $14.45 \mathrm{I}$ & 18.610 & 16.45 & 20.22 \\
\hline & & & & & & & 17.10 & 21.09 \\
\hline & & & & & & & 16.35 & 21.12 \\
\hline Aver. & 14.834 & I 8.268 & 14.425 & 18.579 & 14.419 & $18.57^{\circ}$ & 17.15 & 21.082 \\
\hline "Tokayi "A" & $10.17 x$ & I2. 601 & II .080 & 13.710 & II . 308 & I 3.988 & 14.15 & $17 \cdot 43$ \\
\hline & 10.046 & 12.449 & II. I3O & I 3.775 & II. 320 & 14.002 & I $3 \cdot 5^{8}$ & 16.80 \\
\hline & IO. I7 I & $12.60 \mathrm{I}$ & II . I 90 & 13.860 & I0.970 & 13.600 & 14.02 & $17 \cdot 32$ \\
\hline & 10.200 & 12.637 & I0.860 & 13.443 & II. 104 & 13.735 & I 3.85 & 17.15 \\
\hline & & & 10.908 & $13 \cdot 490$ & II .355 & 14.040 & 14.30 & 17.66 \\
\hline & & & & & & & 14.20 & 17.56 \\
\hline Aver. & IO. 147 & 12.572 & II .033 & 13.655 & It. $2 \mathrm{II}$ & 13.873 & 14.017 & $17 \cdot 32$ \\
\hline Tokayi "B" & I I .392 & 14.08 & I I .034 & I 3.654 & II. I6o & 13.808 & I5.00 & 18.47 \\
\hline & 11.200 & 13.87 & I I. .069 & 13.686 & II . 250 & 13.913 & 14.25 & 17.43 \\
\hline & & & & & & & 13.75 & 17.045 \\
\hline & & & & & & & $\mathrm{I} 3.40$ & 16.57 \\
\hline Aver. & I I . 296 & I3.975 & I I .05 I & 13.670 & II . 205 & I 3.860 & 14.10 & 17.379 \\
\hline
\end{tabular}

When using the vaporimeter to determine the percentage of alcohol in beers and other fermented liquors containing free carbon dioxide, it is directed to treat the liquid in question with an appreciable quantity ( $\mathrm{r}$ teaspoonful to the fluidounce) of finely powdered, freshly calcined lime and then to filter. After repeated trials on the beers examined it was found that the readings were invariably lower than in the distillation and refractometer methods, ranging from 0.3 to 0.5 of I percent. No mention was made in the directions for using the vaporimeter for 
making the liquor up to original volume by washing the lime on the filter with distilled water. However, when this was done the percentage of alcohol was reduced by approximately the same amount as the dilution with water would lead one to expect. It was concluded that a certain quantity of alcohol was held on the filter by the hydrated lime, in such a way that it could not be washed out. Beers that were freed of their carbon dioxide by agitation and with which no lime was used checked within 0. I of one percent with the determinations made by distillation and also with those made by the refractometer. Vaporimeter determinations were made on the beers in question, using freshly SLAKED lime instead of freshly CALCINED lime. The results checked quite closely with the determinations in which the calcined lime was employed. The only difference was a slightly greater variation.

Determinations by distillation and refractometer methods gave an average check of about 0.05 of I percent, although the variations sometimes amounted to as much as $0 . \mathrm{r}_{5}$ of I percent. Attention should be called at this point to the importance of having the liquid of which the refractometer readings are being taken at exactly $20^{\circ} \mathrm{C}$.

Conclusions (Beers).--It is impractical to use the process of evaporation for the determination of alcohol in beers or preparations high in extractives and containing less than 5 percent of alcohol. It is concluded that the best way to free a fermented liquor of $\mathrm{CO}_{2}$ for use in the vaporimeter is by agitation, the use of freshly calcined lime and also freshly slaked lime giving low results.

The alcoholic analyses of five wines was then undertaken for the purposes aforementioned. By the evaporation method it was noted that in every sample (excepting Tokayi A) the percentage ran higher than by the distillation method.

These differences appear greater as the concentration of alcohol increases. It was noted that Tokayi A was higher in solids than Tokayi $B$, which may account for this exception. Higher results obtained by the evaporation method on wines may be attributed to the variation in the volatile constituents present. It appears that samples showing approximately the same percentages of alcohol by distillation will vary when run by evaporation; the sample having the larger amount of solids running the lower of the two in alcohol. The vaporimeter determinations invariably gave higher results. As in the case of beers, wines freed from their carbon dioxide by agitation invariably ran higher than those in which freshly calcined or slaked lime had been used. It should be remembered that in the case of wines the extractive materials are much more in evidence than in beers, and as the vapor pressure of the wine would be the sum of the vapor pressures of all its constituents it is in no way unusual that the percentage as read from this instrument will be too high. Therefore, while the results obtained by the vaporimeter method in the case of beers have been the more satisfactory, it is questionable whether this instrument can be used with any degree of accuracy with wines, the distillation method when corroborated by the refractometer method is much to be preferred.

Department of Pharmaceuticai, Chemistry, Colifege of Pharmacy, UNIVERSITY OF MINNESOTA. 